\title{
THE ACTION OF SODIUM BENZYL CYANIDE WITH CINNAMIC ESTER.
}

BY S. AVERY AND G, R, MCDOLE.

Received January 29 , I908.

\section{Introduction.}

Victor Meyer and his pupils ${ }^{1}$ have studied the character of the methylene hydrogen atoms in benzyl cyanide. They found, in brief, that these atoms resembled in some respects the corresponding atoms in acetoacetic ester and in malonic ester. The reactions studied related in general to the condensation with aldehydes, and to the substitution of alkyl radicles. Later Zelinsky and Feldmann ${ }^{2}$ condensed benzyl cyanide and methylene iodide, forming the nitrile of symmetrical diphenylglutaric acid. Michael ${ }^{3}$ has shown that sodium acetoacetic ester, as also sodium malonic ester, forms addition products with esters of the unsaturated acids. This reaction has been used by Auwers, ${ }^{4}$ Perkins, ${ }^{5}$ Avery, ${ }^{6}$ and others in preparing alkyl glutaric acids. Having had occasion to try to effect the synthesis of certain alkyl glutaric acids the writers decided to study the action of benzyl cyanide on cinnamic ester. It was assumed that an addition product would be formed, which on saponification and the splitting off of carbon dioxide would give a diphenylglutaric acid. The results obtained have shown that the reactions which took place were not strictly analogous to Michael's as the following comparison shows.

Following the analogy of Michael's reaction, we should expect:

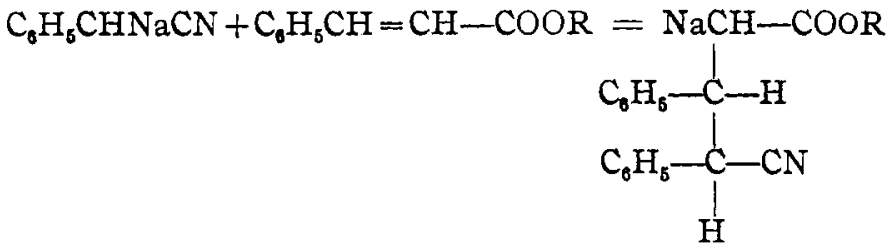

In reality, however, the reaction was accompanied by the saponification of the ester and the two principal products formed were

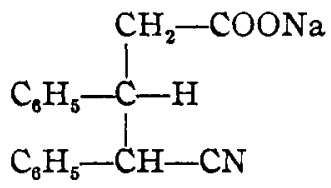

and a product to which we will provisionally ascribe the formula

1 Ber., 20, 534; Ibid., 21, 129 ; Ann., 250, 118.

2 Ber., 22, 3290.

3 J. pr. Chem. [2], 35, 352.

- Ber., 24, 1936.

J. Chem. Soc. (London), 69, 1472.

- Am. Chem. J., 20, 509; Ibid., 28, 48. 


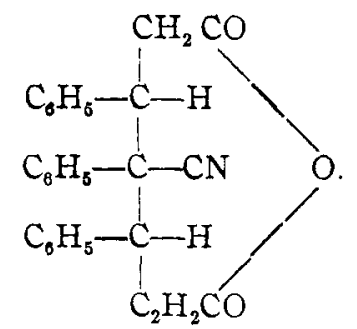

This formula is in harmony with all of the facts observed except the following: It appears to be unchanged by boiling with sodium carbonate or ammonia, either in aqueous or alcoholic solution. Although it is converted into a salt by boiling with alcoholic potassium or sodium hydroxide, the acid liberated from the salt has resisted all attempts to reconvert it into an anhydride.

Of special interest is the formation, easily and in good quantity, of the compound:

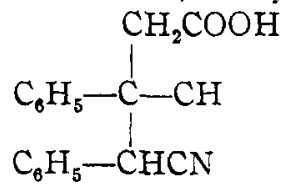

This on reduction may be expected to yield $\beta, \gamma$-diphenyl- $\delta$-aminovaleric acid, which on heating should form the corresponding piperidone derivative. This reduction will occupy our attention in the near future.

\section{Experimental.}

$\beta, \gamma$-Diphenyl- $\gamma$-Cyanbutyric Acid.--Twenty grams of benzyl cyanide were mixed with 30 grams of cinnamic ester, and solid sodium methylate equal to 4 grams of sodium was added with stirring. The mixture became hot and the action was apparently completed in a few minutes. When the action had ceased the product was allowed to stand on the waterbath for two hours. It now appeared as a viscous semi-crystalline yellow mass. On adding hydrochloric acid and stirring, it changed to a very viscous oily mass which on thoroughly acidifying and washing out the sodium chloride, gradually assumed a semi-crystalline condition. This was dissolved in hot benzene and on cooling hair-like needles separated out. On filtering off the mother liquor and condensing, a second crop of crystals was obtained. With careful manipulation the yield amounted to nearly 80 per cent. Almost equally good results were obtained when solid sodium hydroxide was used instead of sodium methylate.

During the reaction the escape of alcohol vapors was noticed.

The acid obtained was recrystallized from benzene. It melts at $161.5^{\circ}$, is easily soluble in alcohol, ether and hot benzene, difficultly soluble in hot and almost insoluble in cold water. Glistening white needles from benzene or dilute alcohol. 


$\begin{array}{llll}\text { The analysis gave: } & \mathrm{C}, 76.67 & \mathrm{H}, 5.84 & \mathrm{~N}, 5.19 \\ \text { Calculated for } \mathrm{C}_{17} \mathrm{H}_{15} \mathrm{O}_{2} \mathrm{~N}: & \mathrm{C}, 76.98 & \mathrm{H}, 5.66 & \mathrm{~N}, 5.28\end{array}$

Titration, 0.2 IOI gram required $7.55 \mathrm{cc}$. $\mathrm{N} /$ Io sodium hydroxide. Theory for one acid $\mathrm{H}$ in $\mathrm{C}_{17} \mathrm{H}_{15} \mathrm{O}_{2} \mathrm{~N}$ requires $7.52 \mathrm{cc}$.

The silver salt is a white insoluble powder, which gave 29.0 I per cent. Ag. Calculated: 29.03 per cent.

a, $\beta$-Diphenylglutaric Acid.-This acid was first prepared by us by adding sodium ( $\mathrm{I}$ atom) dissolved in ethyl alcohol to benzyl cyanide (I molecule). After the action had ceased a molecular quantity of cinnamic ester was added. The action proceeded with the liberation of considerable heat. The resulting mass was viscous and light brown in color. This was acidified with hydrochloric acid and the sodium chloride washed out. The mass resisted all attempts to recrystallize. Attempts were made to saponify with potassium hydroxide, in one instance the compound above mentioned, the half nitrile acid was obtained in a very impure state. As a whole the saponification with potassium hydroxide was unsatisfactory and a product free from nitrogen could not be obtained by this method. The viscous mass was sealed in a Carius tube with concentrated hydrochloric acid and heated for five hours to $150^{\circ}$. The mass was extracted with boiling water several times and the remaining mass reheated and the process repeated. The aqueous extractions were condensed and a crystalline product was obtained which showed, under the microscope, crystals having both cubical and needle-like shapes. Varying products were obtained which melted from $195^{\circ}$ to $215^{\circ}$. By careful recrystallization out of 50 per cent. alcohol the pure diphenylglutaric acid was obtained which melted at $223-4^{\circ}$. The crystals are needles. By working over the mother liquors from these recrystallizations, crystals of a cubical appearance were isolated. It was impossible to get very satisfactory melting points of any of the lower melting products but by repeated recrystallizations a substance was obtained melting almost constantly at $205^{\circ}$. This compound resembled the diphenylglutaric so closely that it was for a time thought to be a stereoisomer. Analysis for carbon and hydrogen agreed very closely with that of the glutaric acid, melting at $223^{-} 4^{\circ}$, and it formed an anilic acid which, though it melted about $30^{\circ}$ lower, corresponded very closely in other respects with that obtained from the glutaric. However, very careful work showed the presence of a small amount of nitrogen in the supposed isomeric glutaric acid $\left(\mathrm{m} .205^{\circ}\right)$ and when this compound was placed in the sealed tube with hydrochloric acid and heated, the compound obtained was in every case the diphenylglutaric acid, melting at $233-4^{\circ}$ and free from nitrogen. The cyanide group was either saponified or converted into insoluble combinations.

The diphenylglutaric acid can be obtained in quantity and without 
the formation of objectionable by-products by heating the $3, y$-dipheny-1 $\gamma$-cyanbutyric acid with concentrated hydrochloric acid in a sealed tube to $150^{\circ}$ for three hours.

The analysis of $a_{1} ;$-diphenvlglutaric acid obtained as first mentioned gave: $\mathrm{C}, 71.86 ; \mathrm{H}, 5.33$. Calculated for $\mathrm{C}_{17} \mathrm{H}_{16} \mathrm{O}_{1}: \mathbf{C}, 71.79 ; \mathrm{H}, 5.67$.

Titration, O.II42 gram of substance required 8.0 I cc. $\mathrm{N} /$ IO $\mathrm{NaOH}$. Theory for $\mathrm{C}_{17} \mathrm{H}_{16} \mathrm{O}_{4}, 8.03 \mathrm{ce} . \mathrm{N} /$ Io $\mathrm{NaOH}$.

The silver salt gave 43.34 per cent $\mathrm{Ag}$. Theory for $\mathrm{C}_{17} \mathrm{H}_{14} \mathrm{O}_{4} \mathrm{Ag}, 43.35$ per cent.

Analysis ${ }^{1}$ of the diphenylglutaric acid obtained by the saponification of the $\beta, \gamma$-diphenyl- $\gamma$-cyanbutyric acid gave: $\mathrm{C}, 71.59 ; \mathrm{H}, 5.69$. Calculated for $\mathrm{C}_{17} \mathrm{H}_{13} \mathrm{O}_{4}: \mathrm{C}, 71.69 ; \mathrm{H}, 5.67$.

Titration, 0.1084 gram of substance required $4.05 \mathrm{cc} . \mathrm{N} / \mathrm{I} O \mathrm{NaOH}$. Calculated for two acid hydrogens in $\mathrm{C}_{17} \mathrm{H}_{13} \mathrm{O}_{4}, 3.99$ cc. $\mathrm{N} /$ IO $\mathrm{NaOH}$.

The Anhydride.--Attempts were made to prepare the anhydride both by heating the acid above its melting point and by treatment with acetyl chloride and acetic anhydride. In all cases a brown product resulted which resisted our attempts to obtain it in a crystalline form.

Anilic Acid.--The anilic acid was prepared by heating some of the glutaric acid with acetyl chloride and boiling off the excess of acetyl chloride. It was then treated with the calculated amount of aniline dissolved in alcohol. The anilic acid separates out of dilute alcohol in flat needle-like erystals having a beautiful mother of pearl luster when dry. Soluble in ether and alcohol. I'urified by recrystallizing out of alcohol. Melting point, $23^{()-2^{\circ}}$.

Titration, 0.1537 gram of substance required 4.25 cc. $\mathrm{N} / \mathrm{I} O \mathrm{NaOH}$. Theory for $\mathrm{C}_{23} \mathrm{H}_{21} \mathrm{ON}_{3}, 4.28 \mathrm{cc} . \mathrm{N} ; 10 \mathrm{NaOH}$.

The nitrogen determination gave 4 .I6 per cent. N; calculated, 3.93 per cent.

Other Products formed by the Action of Sodium Benzyl Cyanide on Cinnamic Ester.-Dry sodium methylate representing 4 grams of sodium was mixed with 20 grams of benzyl cyanide and the mixture heated to $170^{\circ}$. This was now added to 30 grams of hot cinnamic ester and the heating continued with constant stirring at the above temperature for ten minutes. The mass was cooled, treated with strong hydrochloric acid, well washed with water and then boiled with 95 per cent. alcohol. Partial solution took place accompanied by the separation of white crystals, which increased on cooling the mixture. These were filtered off, washed with a little alcohol, then a small quantity of benzene, dried and boiled with sodium carbonate solution, again filtered and dried. Yield, 9 grams.

After having tried all of the ordinary solvents without satisfactory 1 Analysis by $\mathrm{C}$. J. Frankforter. 
results, amyl alcohol was found to be well suited for the purpose of recrystallization. The pure compound forms long obliquely pointed plates, sometimes resembling needles, which melt at $23 \mathrm{I}^{-} 3^{\circ}$. Insoluble in ammonia, sodium carbonate solution, and petroleum ether; difficultly soluble in alcohol, ether and benzene, soluble in hot acetic acid and amyl alcohol. It is unchanged by heating in a sealed tube with concentrated hydrochloric acid for 5 hours. It is, however, acted upon by a strong solution of alcoholic potash. The analysis corresponded to the formula $\mathrm{C}_{28} \mathrm{H}_{21} \mathrm{O}_{3} \mathrm{~N}$. From all data at hand it corresponds to the anhydride of the acid resulting from the union of two molecules of cinnamic ester with one of benzylcyanide.

The following formula expresses this constitution but is put forth only tentatively:

The analysis gave: ${ }^{\mathrm{C}}, 78.93 ; \mathrm{H}, 5.59 ; \mathrm{N}, 3.64$. Calculated for $\mathrm{C}_{26} \mathrm{H}_{21} \mathrm{O}_{3} \mathrm{~N}: \mathrm{C}, 79.04 ; \mathrm{H}, 5.34 ; \mathrm{N}, 3.55$.

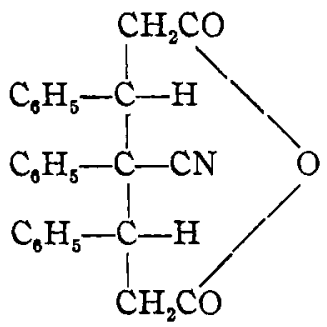

The molecular weight was determined by the freezing point method, using benzene as a solvent. The substance is so slightly soluble in this substance that the determinations were not very satisfactory. The mean of the two determinations gave 388 as the moleculat weight. Calculated for $\mathrm{C}_{26} \mathrm{H}_{21} \mathrm{O}_{3} \mathrm{~N}, 396$.

The Acid Obtained from the Supposed Anhydride.-When the compound last considered is heated for ro minutes with very strong alcoholic potash it is dissolved and a sodium salt is obtained. This, upon acidifying, yields the corresponding acid. The acid was purified by dissolving in ether and evaporating the ether off in the presence of benzene. This was allowed to crystallize and recrystallized again out of 50 per cent. alcohol. The substance crystallizes in rectangular plates and under some conditions in crystals resembling cubes suggesting the impurity encountered with the $a, \beta$-diphenylglutaric acid. Soluble in ether and alcohol, sparingly soluble in benzene, and boiling water. Melts at $213^{\circ}$.

The analysis gave: $\mathrm{C}, 75.38 ; \mathrm{H}, 5.56 ; \mathrm{N}, 3.69$. Calculated for $\mathrm{C}_{28} \mathrm{H}_{23} \mathrm{O}_{4} \mathrm{~N}: \mathrm{C}, 75.54 ; \mathrm{H}, 5.56 ; \mathrm{N}, 3.39$.

Titration, 0.2530 gram of substance required $12.05 \mathrm{cc}$. of $\mathrm{N} / \mathrm{IO} \mathrm{NaOH}$. Theory for $\mathrm{C}_{28} \mathrm{H}_{23} \mathrm{O}_{4} \mathrm{~N}$, I $2.2 \mathrm{cc}$. N/IO $\mathrm{NaOH}$.

1 Analysis by C. J. Frankforter. 
Silver salt is an insoluble white powder, darkening slightly upon exposure to light. It gave 34.40 per cent. Ag; calculated, 34.24 per cent.

We have attempted to saponify the cyanogen group of this compound and thus obtain the tricarboxylic acid but it has resisted all attempts. Neither potassium hydroxide nor hydrochloric acid in a sealed tube gave the desired result. We expect to investigate the character of this nitrogen atom and the salts of the acid more fully, as well as the exact constitution of the anhydride from which it was formed.

CHEMTCAL I,ABORATORY,

ITIVERSITY OF NEBRASKA

LINCOLN, NEH.

\title{
THE SYNTHESIS OF CERTAIN AROMATIC SUCCINIC ACIDS.
}

\author{
BY S. AVERY AND FRED W. UPSON. \\ Received January 29 , I908.
}

In the preceding article by one of us and McDole it is pointed out that in the synthesis of a,3-diphenylglutaric acid apparently two stereoisomers were obtained. It was conceived, however, that one of these might be the isomeric stccinic acid formed according to the reaction: $\mathrm{C}_{6} \mathrm{H}_{5}-\mathrm{CH}=\mathrm{CHCOOR}+\mathrm{C}_{6} \mathrm{H}_{5}-\mathrm{CHNa}-\mathrm{CN}=\mathrm{C}_{6} \mathrm{H}_{5}-\mathrm{CHNa}-\mathrm{CH}-\mathrm{COOR}$<smiles>N#CC(c1ccccc1)c1ccccc1</smiles>

This ester on saponification would yield the unknown benzyl-phenylsuccinic acid.

For the purpose of comparing this acid with the product described in the preceding article it was decided to effect its synthesis in such a way as to leave no doubt in regard to its constitution.

Accordingly 25 grams of sodium benzylmalonic ester were condensed with 2 I grams of bromphenylacetic ester. The heavy brown oily product thus obtained was heated in a bomb with hydrochloric acid but no crystalline product was obtained, although a large amount of carbon dioxide was liberated. The oil was then boiled with potassium hydroxide solution, in which it partially dissolved. On separating from the undissolved portion and acidifying, crystals mixed with an oil came down. This mixture was extracted several times with hot water, which on cooling deposited crystals in a fairly pure state. These were filtered off and washed free from oily and resinous matter with a mixture of chloroform and petroleum ether. After recrystallization from a mixture of ether and chloroform, pure white, very fine, needle-like crystals melting sharply at $176^{\circ}$ were obtained. The acid is difficultly soluble in hot, almost insoluble in cold water; soluble in ether and alcohol; insoluble in chloroform and petroleum cther and difficultly soluble in benzene.

Titration. - 0.0615 gram acid required $4.25 \mathrm{cc}$. N/Io sodium hydroxide; calculated for 2 acid hydrogens in $\mathrm{C}_{17} \mathrm{H}_{15} \mathrm{O}_{4}, 4.32 \mathrm{cc}$. 